Here is a perfect demonstration evident to the senses. But let us go one step further. The rectangles in the preceding theorem may be bisected by diagonals and set round the square of the difference in such a manner as to form the square of the hypothenuse of the right-angled triangle, the sides of which are also those of the assumed squares. The squares of the sides of a rightangled triangle, therefore, are together equal to the square of the hypothenuse, since the former may be changed into the latter.
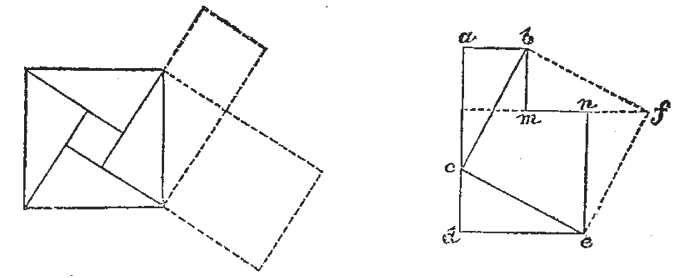

The same conclusion may be arrived at by a still shorter and simpler course. Let any two squares be joined together as in the annexed figure, or, rather, let them be cut in paper in one piece. Then take $a c$ equal to the side of the greater square, and join $b c$ and $c e$. Cut off the two equal triangles $b a c$ and $c d e$, and place them in the positions of $b m f$ and $f z e$, and the two squares will be thus transformed into the square of the hypothenuse of the right-angled triangle, of which they form the sides.

Thus we have at once a demonstration of the famous Pythagorean theorem (Euclid i. 47), and have attained with three or four steps the same height climbed by Euclid with forty-seven. The words of his demonstration, committed to memory by a child, remain there mere words and nothing more. Words serve to mark and denote ideas, but cannot create them, where the material of ideas does not already exist. But the child who with paper or card amuses himself in going over the visible demonstration suggested in this letter, in varions forms and repeatedly-for veither old nor young can be said to learn a truth merely by its transient recognition-will assuredly awaken to an agreeable consciousness of the reasoning faculty, and feel no difficulty in future geometrical studies.

In 1860 there was published for me, by Messrs. Williams and Norgate, a little volume entitled, "The Elements of Geometry Simplified and Explained," adapted to the system of empirical proof, and of exhibiting the truth of theorems by means of figures cut in paper. It contained in thirty five theorems the quintessence of Euclid's first six books, together with a supplement of thirty-three not in Euclid. There was no gap in the sequence or chain of reasoning, yet the 32 nd and 47 th provisions of Euclid were respectively the $3 \mathrm{rd}$ and $\mathrm{I}$ th of my series. This book proved a failure, for which several reasons might be given, but it will be sufficient here to state but one, namely, that it came forth ten years before its time. What became of it I know not. But of this I am convinced, that though I failed, success will attend those who follow in my footsteps.

W. D. CoOley

THE discussion in your last part on methods of teaching elementary geometry reminds me that at a period when I was teaching the subject to a considerable number of pupils, I fre. quently overcame the difficulties of very young or inapt students by commencing with the study of a solid, such as a cube, encouraging the pupils to frame definitions for the parts of the object. The ideas existing in the child's mind of a solid, a plane, a line, and a point, were thus put into words in an order the reverse of that in which they would have been had Euclid been used. The chief properties of parallelograms and triangles followed, and were easily discovered by the use of a pair of compasses, scissors, and paper, and that at an age when Euclid was a sealed book. I believe children can be most easily taught to solve problems in plane geometry when they occur in connection with early instruction in practical solid geometry. Most children try to draw, and if they were encouraged to represent simple objects by "plans" and " elevations," the necessity of obtaining a knowledge of how to describe the forms presented to them would frequently carry the pupils through a large number of the principal problems of plane geometry witl a pleasure they could not experience if the "problems" were put before them, without any reason for their solution but the teacher's command. The powers of truthful representation gained by such teaching, would be of the utmost value to thousands who would never attempt to learn "Euclid;" whilst, so far as I am able to judge, it is more likely to prepare the boy to read formal works on geometry with pleasure than to create a distaste for the study.

Woolwich, October 9

THOMAS JONES

\section{The Coming Eclipse}

I HAVE been very much interested in Mr. Lockyer's lecture at the Royal Institution on the late eclipse. I am especially glad that he is at length able to acknowledge the existence of com. paratively cool hydrogen, because in my Eclipse Report of I868 (vol. xxxvii. Part I, R.A.S. Memoirs), I stated that I believed from the evidence of the photographs that hydrogen was dispersed from the prominences in visible streams in some cases, and in others invisibly.

But while Mr. Lockyer admits this, he seems to me very unnecessarily to avoid everywhere the use of our familiar term "atmosphere" to include the whole gaseous envelope of the sun. This seems to me to be the sense in which Kirchhoff used the word when he said it was extensive, ${ }^{*}$ It certainly was the sense in which I used it, and, I believe, that in which all who spoke of an extensive atmosphere did so use it. In this sense there can be no doubt that the sun has an extensive atmosphere, the outer portion of which is comparatively cold and capable of reflecting light if the polarisation now not doubted be due to reflection.

There is one consideration which, however, does not seem to have occlirred to Mr. Lockyer. If the cold atmosphere, as I will venture still to call it, reflect the prominence light, it will also reflect the solar light. Its reflected light then should be such as reaches us at ordinary times, and not so exclusively chromospheric. Adding to this the light which is due to cool hydrogen, we should have, I anticipate, a faint continuous spectrum with the bright line $F$, and also a solar spectrum with, perhaps, some of the chromospheric lines reversed. That is not what has been found, and I do not at present see any way of reconciling the facts with the theory that the undoubted polarisan tion is due to reflection.

Before going to another subject, I would wish to direct attention to my friend Captain (now Major) Branfill's observations in I $868+$ on the polarisation of the corona. Mr. Proctor, indeed, in his book on the Sun, says that the Astronomer Royal did not consider them conclusive, but I have his official statement that he did so consider them, and an inquiry as to Mr. Proctor's authority leads me to think that Mr. Airy's meaning was mistaken. I think any one who reads the account in the original will feel that the plane of polarisation was satisfactorily determined. An observer in 1870 has said that he found the bands of Savart persistent. I have not now time to look up the reference, but he used, it seemed to me, the centre of the moon as the centre of rotation. Captain Branfill was careful not to do this, as his figures prove (page 25 of Report).

Now to the future. I have received from Government an inquiry as to recommendations to observers coming out. I am now suggesting, in addition to my own station at Dodabetta, that observers should be stationed at Kotagherry in the Nilgherries, at Manantoddy among the coffee districts to the west, and at Tirupur, close to Avenashy Road Station of the Madras Railway. Of these Manantoddy is the least accessible, but the whole will give a range of stations from 8,600 feet high down to the ordinary level of the plain country. More observers could be accommodated on the Nilgherries, where the weather, I am assured, is likely to be excellent. Of Ceylon I have not satisfactory accounts, nor of the west coast.

If these stations be adopted, I would suggest that, if possible there should be a conference of observers. The possibility will depend on our leisure, which, probably, none of us can now oresee.

I should say that I have made these suggestions without reference to Mr. Pogson, because I know nothing of his plans, having received no answer to inquiries; it is possible those may modify projects, but any visitors should bear in mind that it is almost necessary that some European residences should be close to their stations.

H.M. Mint, Calcutta, Sept. I I J. T. TENNANT

* Mr. Iockyer has long ago shown that the Sun's atmosphere lies partly above and partly below the superior limit of the photosphere. The word Atmosphere was used by Kirchhotf in the manner indicated, because he believed the photosphere to be liquid.- $\mathrm{ED}$.

$\dagger$ American observers seem never to have seen the Report. 